\title{
IDEOLOGIA E EDUCAÇÃO: O CONFLITO DE CLASSES NA RELAÇÃO PROFESSORA E AUXILIAR DE PROFESSORA
}

\author{
JÉSSICA TAVARES LUZ \\ PROF. - DR. ${ }^{a}$ CASSIA DOMICIANO
}

\begin{abstract}
RESUMO
Este artigo mostra e discute os resultados de pesquisa realizada em uma escola privada do município de São Paulo que atende da Educação Infantil ao Ensino Médio. Essa pesquisa correspondeu ao Trabalho de Conclusão de Curso (TCC) da pesquisadora apresentado à Universidade Metodista de São Paulo para obtenção do grau de licenciado em Pedagogia, sob a supervisão da professora orientadora. O objetivo desta investigação foi compreender o conflito de classe existente na relação professora e auxiliar de sala, na etapa da educação Infantil. A investigação adotou a abordagem qualitativa e por meio da pesquisa de campo, com o uso da técnica da pesquisa participante, todas as falas das professoras e das auxiliares que explicitavam os conflitos de classe foram anotadas constantemente em diário digital no período de outubro de 2016 a abril de 2017. Após leitura, sistematização e análise dos registros, pudemos indicar que o professor, em sua atividade docente e nas relações que estabelece, adota uma dualidade ideológica (ideologia teórica e ideologia prática), e utiliza a estigmatização, enquanto fenômeno ideológico, para adotar um comportamento discriminatório em relação às auxiliares.
\end{abstract}

Palavras-chave: Ideologia. Estigmatização. Ideologia Docente.

\begin{abstract}
This article presents and discusses the results of research carried out in a private school in the city of São Paulo that attends the kindergarten to high school. This research corresponded to the Work of Completion of the Course (WCC) of the researcher
\end{abstract}


presented to the Methodist University of São Paulo to obtain a degree in Pedagogy, under the supervision of adviser professor. The objective of this research was to understand the class conflict existing in the relationship between teacher and classroom assistant in the stage of Early Childhood Education. The research adopted the qualitative approach, and through the field research, with the use of the participant research technique, all the statements of the teachers and of the auxiliaries that explicit the class conflicts were annotated constantly in digital newspaper in the period of October of 2016 to April 2017. After reading, systematizing and analyzing the records, we were able to indicate that the teacher adopts an ideological duality (theoretical ideology and practical ideology) in his teaching activity and in the relations he establishes, and uses stigmatization as an ideological phenomenon, to adopt discriminatory behavior in relation to auxiliaries. Key-words: Ideology. Stigmatization. Teaching Ideology.

\section{INTRODUÇÃO}

A ideologia está presente em todos os discursos e todas as relações existentes na sociedade. Os indivíduos têm, por detrás do seu comportamento, uma posição ideológica. O foco deste artigo é analisar a influência das noções ideológicas nas relações estabelecidas entre professoras e auxiliares de professoras $^{1}$ que atuam na educação infantil, em um colégio confessional no município de São Paulo.

A ideologia está mascarada pela naturalidade das ações e, por esse motivo, se torna difícil identificar ações e comportamentos que foram pautados por questões ideológicas. A partir de um posicionamento ideológico, o sujeito tende a adotar determinado comportamento, e esse comportamento pode caracterizar-se como estigmatização. Por estigmatização entende-se as atitudes que um indivíduo adota em relação a outro, movido pelo fato de acreditar que por algum motivo essa outra pessoa possui algum

\footnotetext{
As auxiliares são profissionais que prestam apoio às professoras titulares de classe, profissionais que, geralmente, encontram-se em formação ou são recém-formadas em cursos de Pedagogia.
} 
atributo depreciativo, esteja esse atributo relacionado a questões físicas ou sociais (GOFFMAN, 1980).

De maneira mais ou menos consciente, cada indivíduo possui um posicionamento ideológico que norteia suas atitudes nas relações sociais (HARNECKER, 1983), e isso não é diferente nas relações estabelecidas dentro das instituições de ensino.

A inculcação e naturalização das ações é uma das hipóteses para justificar o mascaramento das questões ideológicas nas relações humanas; outra hipótese sugere que os indivíduos, quando organizados em grupo, adotam um comportamento padrão de grupo e suas ações visam manter a hegemonia desse grupo em relação aos demais.

Neste artigo, investiga-se a relação entre professoras e auxiliares buscando identificar se na maneira como se relacionam existem condutas determinadas pelo comportamento padrão de grupo, e se a ideologia é uma questão determinante na forma que esses grupos se relacionam.

Para tal, apoia-se nos conceitos de ideologia exibidos por M. Harnecker (1983), nos conceitos de estigma e a relação de estabelecidos e estigmatizados apresentada por E. Goffman (1980), e N. Elias e J. Scotson (2000), além dos conceitos de ideologia docente de D. Saes (2005; 2007).

A pesquisa adotou técnicas qualitativas de análise, pois acreditamos que permitiriam examinar os aspectos que envolviam a relação professor-auxiliar de sala com mais profundidade.

Para tanto, empreendemos uma pesquisa de campo, fazendo uso da observação participante. Conforme C. Selltiz, M. Jahoda, M. Deutsch e S. W. Cook (1974), neste tipo de pesquisa, o pesquisador responsável pela coleta de dados está inserido no grupo a ser analisado, registra diariamente dados relevantes para a produção, reflexão e análise do trabalho. Além disso, a observação permite um relato daquilo que os sujeitos praticam (consciente ou inconscientemente) por meio de suas atitudes, o que nem sempre é viabilizado por outra metodologia de pesquisa.

O período de coleta de dados ocorreu de outubro de 2016 a abril de 2017. Durante esse intervalo, a pesquisadora anotou em diário digital os fatos e as narrativas que estavam diretamente 
vinculados ao objetivo desta pesquisa. Tais ocorrências eram registradas de maneira constante e diária. Os arquivos digitais foram organizados por pessoa/função, de modo que para cada participante se obteve um conjunto de informações detalhadas acerca das noções ideológicas que perpassavam sua relação no campo de trabalho.

Após a coleta e o registro, os relatos foram lidos, tendo como foco levantar as ações praticadas pelo grupo investigado que pudessem ser caracterizadas como estigmatizadoras. Posteriormente ao levantamento e análise, classificamos as ações encontradas em dois grupos: ações estigmatizadoras relacionadas à função e à formação. Tais ações serão brevemente apresentadas e discutidas neste artigo. Ressaltamos que para preservar a identidade dos envolvidos, optamos por colocar as iniciais de seus respectivos nomes, bem como, omitir o nome da escola em que a pesquisa ocorreu.

Como resultados da investigação, pudemos trazer para o debate que o professor, em sua atividade docente e nas relações que estabelece, adota uma dualidade ideológica (ideologia teórica e ideologia prática), e como utiliza a estigmatização, enquanto fenômeno ideológico, para adotar um comportamento discriminatório em relação às auxiliares.

\section{CONCEITOS QUE SUBSIDIARAM A PESQUISA}

\subsection{Conceito de ideologia e classe social}

Entre os conceitos necessários para discutir as relações estabelecidas entre os professores titulares de classe e as auxiliares está o de ideologia. Para autores como Harnecker (1983), tal conceito está ligado à teoria marxista de Marx e Engels. Segundo essa autora, a ideologia está impregnada em todas as atividades do homem, não somente nas relações de produção. Com base nessa afirmação, conclui-se que a ideologia afeta inclusive as relações estabelecidas com os demais membros da sociedade e as características individuais dos sujeitos, e, desse modo, nenhuma ação é livre da ação invisível da ideologia. 
Para a autora, existem dois sistemas dentro do nível ideológico: o sistema de ideias ou representações sociais (que tem por objetivo fornecer ao indivíduo a capacidade de se adaptar à sua realidade, de maneira que seja possível a este, seguir mantendo a esperança ou a motivação necessárias) e o sistema de atitudes ou comportamentos sociais (correspondente aos hábitos e atitudes adotados pelo indivíduo a partir da percepção que esse tem do seu lugar na sociedade, que nem sempre estará condizente com a realidade).

A ideologia tem por principal função assegurar as relações dos indivíduos entre si e com a sua condição de existência, de maneira a tornar possível a adaptação desses indivíduos nas suas funções dentro da organização social (HARNECKER, 1983). Para a autora:

A ideologia se destina, neste caso, a assegurar a coesão dos homens na estrutura geral da exploração de classe. Destina-se a assegurar a dominação de uma classe sobre as demais, fazendo os exploradores aceitar suas próprias condições de exploração como algo fundado na 'vontade de Deus', na 'natureza', ou no 'dever moral' e assim por diante [...] ela serve também aos indivíduos da classe dominante para reconhecer os sujeitos dessa classe, para aceitar como 'vontade de Deus', como 'fixada pela natureza' ou pelo 'dever moral', a dominação que exercem sobre os explorados (HARNECKER, 1983, p. 103, 104).

Desse modo, é possível afirmar que a principal função da ideologia é assegurar que cada pessoa desempenhe determinado papel na sociedade hierarquicamente organizada, sem questionar, e sem se manifestar. É importante a compreensão e a aceitação de que tal posicionamento (vantajoso ou não) foi determinado por fatores que estão fora do controle do sujeito, e cabe a ele desempenhar o seu papel da melhor maneira possível.

É imprescindível, principalmente para o grupo que compõe a classe burguesa na sociedade capitalista, que todos aceitem como verdade o fato de que pessoas que possuem uma colocação 
melhor dentro da organização social desempenhem o papel de exploradores por serem pessoas com melhores aptidões; já as pessoas que se submetem à exploração, submetem-se por serem pessoas de menor valor humano, com menos aptidões ou capacidades.

Por esses motivos, é tão importante que a ideologia permaneça oculta, pois assim as pessoas não se revoltam contra o atual funcionamento da sociedade, deixando de comprometer sua organização e funcionalidade.

Um conceito importante dentro da ideologia trata-se das regiões ideológicas. Essas regiões são particulares e operam de maneira quase que individualizada, possuem suas próprias regras, motivações e crenças. São exemplos dessas regiões: a ideologia moral, a ideologia religiosa, filosófica, profissional, política, entre outros (HARNECKER, 1983).

Para cada uma dessas regiões, a ideologia pode se apresentar sob duas formas diferentes: a forma de ideologias práticas e ideologias teóricas. As ideologias práticas são as que exibem um perfil menos reflexivo, já as ideologias teóricas mostram um perfil mais reflexivo, mais sistematizado, ou seja, uma maneira mais consciente de ideologia (HARNECKER, 1983).

Portanto, pode-se dizer que a ideologia prática é aquela dentro das regiões ideológicas relacionada à prática, ou seja, àquilo que o indivíduo faz e a maneira como se comporta; por conseguinte, a ideologia teórica diz respeito ao discurso que o indivíduo adota dentro de determinada região ideológica, ou seja, é aquilo proferido pelo indivíduo.

Perceber a diferença entre ideologia teórica e ideologia prática é o que permite entender a dualidade ideológica do indivíduo, pois ele pode alternar-se entre ideologia teórica e ideologia prática.

Outro conceito importante e que não pudemos ignorar para a análise dos dados levantados é o de classes sociais.

A atual sociedade está organizada em diferentes classes. Para melhor compreender essa organização, faz-se necessário compreender a concepção de classe social apresentada pela teoria marxista: 
São grupos sociais antagônicos em que um se apropria do trabalho do outro por causa do lugar diferente que ocupam na estrutura econômica de um modo de produção determinado, lugar que está determinado fundamentalmente pela forma específica em que se relaciona com os meios de produção (HARNECKER, 1983, p. 157).

A sociedade capitalista de classes está dividida em dois grupos básicos: a classe burguesa, detentora dos meios de produção, e a classe trabalhadora, não possuidora dos meios de produção, que para se sustentar vende sua mão de obra em troca de pagamento.

A relação existente entre essas duas classes é mantida pela exploração da força de trabalho exercida pela burguesia para com a classe trabalhadora, uma vez que essa força de trabalho é considerada uma mercadoria (LINHARES; MESQUIDA; SOUZA, 2007).

Em síntese, classe social é o termo adotado para indicar a separação entre as pessoas de acordo com a posição ocupada dentro da organização social capitalista (HARNECKER, 1983).

Nesse sistema, o burguês reproduz sua força de trabalho a partir da classe trabalhadora, extraindo desse trabalho a mais valia, ${ }^{2}$ o lucro como pagamento.

Portanto, o trabalhador vende sua força de trabalho, mas não recebe o pagamento de acordo com o valor final produzido. O trabalhador recebe uma parcela do valor final desse produto, e é desse valor que o trabalhador deverá garantir sua sobrevivência, e a sobrevivência da geração seguinte de trabalhadores (HARNECKER, 1983).

2 Partindo da conceituação de Marx (1988), mais valia compreende o valor gerado - agregado - pelo trabalhador por meio do excedente de seu trabalho durante o processo de produção de determinada mercadoria. $\mathrm{O}$ trabalhador cria mais valor do que o contido na força de trabalho paga pelo capitalista e, conforme Marx, essa diferença entre o criado e o pago, que é apropriada pelo capitalista, é a geradora de lucro e o objetivo último do processo de produção capitalista. 
A relação antagônica existente entre essas duas classes é o que chamamos de luta de classes. Essa luta é caracterizada pelo fato de cada uma das classes defender os seus interesses, que são completamente opostos (HARNECKER, 1983). Acerca da luta de classes Harnecker (1983, p. 184) afirma:

A luta de classes aparece quando uma classe se opõe a outra em ação, e, portanto, só aparece em um determinado momento do desenvolvimento de uma sociedade. Em outras fases de sua evolução, a luta de classes pode aparecer apenas em germe, como no caso das lutas isoladas entre os operários de algumas fábricas e seus patrões, ou nas lutas que, embora mobilizem toda a classe, não conseguem se elevar até o nível de seus próprios interesses de classe; ou como uma luta oculta, latente, quando não existe luta aberta, mas descontentamento latente, oposição surda.

Por fim, a luta de classes pode acontecer no campo ideológico, econômico e político, e ela ocorre quando os indivíduos tomam consciência de sua condição na organização social, seja ela de explorador ou explorado, e a partir disso, buscam melhorias na sua condição dentro da sociedade capitalista.

\subsection{O conceito de estigma e estigmatização}

Tendo em vista que a partir dos relatos das professoras e auxiliares buscamos caracterizar ações estigmatizadoras, não podemos deixar de conceituar estigma e estigmatização.

Para entendermos esses conceitos, faz-se necessário compreender que a sociedade estabelece meios de classificar e categorizar as pessoas com base em diversos critérios, determinados por questões socialmente estabelecidas. Uma vez categorizadas, as pessoas encontram dentro do grupo outros indivíduos semelhantes a elas, portanto, dentro desse grupo sentem-se confortáveis e seguras. Entretanto, começam a surgir evidências de que determinada pessoa possui atributos que a tornam diferente dos demais, em sendo assim, os conflitos começam (GOFFMAN, 1980). 
A palavra "estigma" é empregada quando o atributo que o diferencia dos demais é de alguma forma depreciativo, ou retira dessa pessoa o padrão de normalidade estabelecido pela sociedade ou pelo seu grupo (GOFFMAN, 1980).

Esse estigma é classificado em duas modalidades, colocando o sujeito na condição de "desacreditado" - quando a característica que a distingue das demais pessoas é conhecida - ou "desacreditável" - quando a característica que a diferencia dos demais não é imediatamente perceptível (GOFFMAN, 1980).

Segundo Goffman (1980), existem três tipos de estigmas que podem ser atribuídos às pessoas: as abominações do corpo ou deformidades físicas, as culpas de caráter individuais, e os estigmas tribais (GOFFMAN, 1980). Uma vez compreendido o conceito de estigma, é possível entender quem são os estigmatizados e estigmatizadores.

Estigmatizados são todos os indivíduos que possuem algum atributo dos já citados, ou seja, o estigma que lhe atribui descrédito, ou menor valor humano.

A estigmatização ocorre quando as demais pessoas adotam ações e atitudes depreciativas diante de um atributo encontrado no indivíduo.

Pessoas que assumem uma atitude depreciativa em relação às outras possuidoras de algum estigma julgam-se legitimadas em suas atitudes por se considerarem pessoas superiores, os "estabelecidos". A partir desse comportamento discriminatório, os estabelecidos encontram meios de se manterem superiores em relação aos estigmatizados, e suas atitudes visam manter seu status, e sua posição.

Elias e Scotson (2000) abordam o seguinte: “a opinião interna de qualquer grupo com alto grau de coesão tem uma profunda influência em seus membros, como força reguladora de seus sentimentos e conduta" (ELIAS; SCOTSON, 2000, p. 39), desse modo, a influência exercida pelo grupo sobre seus membros determinará a maneira de agir desses.

Portanto, a sustentação da posição superior do grupo encontra-se na coesão dos membros, e essa superioridade é 
afirmada e reafirmada a partir do comportamento de estigmatização em relação a outros grupos (ELIAS; SCOTSON, 2000).

\section{IDEOLOGIA DOCENTE: O QUE SE ENCONTRA POR TRÁS DAS AÇÕES E DOS DISCURSOS}

\subsection{Ideologia docente}

A categoria docente é um grupo funcional altamente influenciado por questões ideológicas. Além disso, contribui para que a escola mantenha sua função de aparelho ideológico do Estado. ${ }^{3}$

$\mathrm{Na}$ sociedade capitalista, a divisão social que assegura a cada indivíduo um lugar na produção começa na divisão do trabalho e é reforçada na escola por meio da inculcação, para que as gerações seguintes permaneçam aceitando sua condição como algo natural e necessário (LINHARES; MESQUIDA; SOUZA, 2007).

Segundo Perez Gomez (1998):

A função da escola, concebida como instituição especificamente configurada para desenvolver o processo de socialização das novas gerações, aparece puramente conservadora: garantir a reprodução social e cultural como requisito para a sobrevivência mesma da sociedade (PÉREZ GOMEZ, 1998, p. 14).

Portanto, a escola vem contribuindo com a organização capitalista como mecanismo de reprodução social, para que a estrutura capitalista seja perpetuada através das gerações.

A atual classe média é composta por trabalhadores assalariados, e seu trabalho está ligado à produção de maneira indireta, ou seja, nos variados processos que viabilizam a produção. Saes (2007) classifica o professor como membro pertencente à classe média e traz a seguinte contribuição:

3 Além de ensinar conteúdos formais, a escola deve ensinar o aluno a aceitar sua condição submissa à classe dominante; ele deve obedecer às regras vigentes sem se rebelar nem questionar (LINHARES; MESQUIDA; SOUZA, 2007). 
Os professores, enquanto trabalhadores não-manuais, pertencem à classe média. Seu trabalho pode ser mecânico e repetitivo (nesse caso, estamos diante do professor-repetidor) ou criador (nesse caso, pode-se dizer que o professor é um "intelectual” no sentido restrito da palavra). Em qualquer dos dois casos (o do professor-repetidor e o do professor criador), a tendência ideológica prática dos professores consiste em defender os interesses do conjunto dos trabalhadores não-manuais, que buscam valorizar-se econômica e socialmente aos olhos da classe capitalista, em detrimento da classe dos trabalhadores manuais. A ideologia profissional dos docentes não pode negar essa disposição ideológica profunda que envolve todos os trabalhadores não-manuais, dentre eles, os professores (SAES, 2007, p. 110, 111).

Ainda, segundo Saes (2005), o fato de os professores estarem alocados no grupo de trabalhadores não manuais deve-se a terem provado ao longo da vida escolar, por intermédio de provas e concursos, que são competentes para a função.

Marta Harnecker (1983) afirma que existe diferenciação entre ideologia teórica e prática dentro das diferentes regiões ideológicas. Sendo a docência uma categoria profissional, localizada em determinada região ideológica (a região profissional), o professor adota uma dualidade ideológica.

Ideologia teórica refere-se àquelas que possuem um perfil mais reflexivo; estabelece uma relação entre a maneira como o indivíduo se percebe e o discurso que adota (HARNECKER, 1983). A ideologia prática, por sua vez, está ligada à prática, ou seja, no comportamento que o indivíduo adota nas diferentes situações do cotidiano (HARNECKER, 1983).

Aplicando esses entendimentos à carreira docente, podemos concluir que, uma vez que assume uma dualidade ideológica, a ideologia teórica refere-se à ideologia de vida do professor e o discurso que ele adota, e a ideologia prática rege o comportamento que o professor adota no exercício de sua atividade profissional. 


\subsubsection{A ideologia teórica do professor}

A ideologia teórica do professor é aquela que está diretamente ligada ao discurso que o professor adota, seja em sua atividade profissional, ou em sua vida pessoal. A respeito dela Saes (2007) faz a seguinte afirmação:

[...] ideologia da competência adquirida (ou ideologia do mérito pessoal), segundo a qual todo aquele que empreende um grande esforço pessoal e se aplica nos estudos adquire a competência necessária para ser bem-sucedido na vida profissional (SAES, 2007, p. 112).

A ideologia do mérito pessoal, ou meritocracia, afirma que o empenho que o aluno deposita em sua vida escolar produzirá resultados em sua vida profissional, ou seja, quanto maior é a dedicação dos alunos para com os seus estudos, tanto melhores serão suas condições de trabalho (intelectual) (SAES, 2005).

Nessa afirmação, não se levam em conta os fatores econômicos ou sociais de cada pessoa. Não se consideram as diferentes condições e oportunidades em que vivem os sujeitos, o que torna esse discurso incoerente com a realidade dos alunos brasileiros.

Além do discurso da meritocracia, em sua vida pessoal o professor adota a ideologia do dom para justificar seu posicionamento profissional. Nessa concepção ideológica, "a capacidade intelectual não é uma qualidade que todo o indivíduo pode adquirir por meio do esforço pessoal e do estudo, e sim, um atributo concedido desde o nascimento, de modo irreversível e intransferível, a certos indivíduos" (SAES, 2007, p. 113).

Apesar de se tratar de duas vertentes da ideologia teórica do professor, as duas tornam-se conflitantes, pois, se o professor se considera um indivíduo de aptidões e capacidades que lhes foram conferidas ao nascimento, como pode utilizar a meritocracia com seus alunos? Se ao nascermos já somos separados entre indivíduos mais ou menos capacitados, empenho e esforço pessoal na vida escolar não serão capazes de alterar essa realidade.

Não é possível classificar pessoas a partir de seu desempenho escolar, pois em um país com diferentes realidades, os 
indivíduos não competem em condição de igualdade; sempre existirão os que tiveram melhores oportunidades e, por conseguinte, melhores resultados.

\subsubsection{Ideologia prática do professor}

A Ideologia prática trata-se da ideologia que rege as ações do professor durante o exercício de sua prática profissional, ou seja, no trabalho que desenvolve junto aos seus alunos, e essa prática está profundamente ligada à ideologia da classe média, a qual pertence o professor (SAES, 2007).

Vale ressaltar que o professor é um trabalhador, membro da classe média, pois desempenha um trabalho não manual (intelectual), e suas atitudes em sala de aula refletirão o seu posicionamento dentro da hierarquia social (SAES, 2007).

$\mathrm{Na}$ sala de aula, o professor atua como representante ideológico da classe média, promovendo, por meio de práticas pedagógicas de cunho elitista, a valorização relativa dos trabalhadores não-manuais e a desvalorização relativa dos trabalhadores manuais. Essas práticas, porém, são recobertas com a ideologia do mérito, que apresenta a escola como um espaço de reconhecimento dos esforços pessoais (SAES, 2007, p. 112).

Portanto, em sua prática, o professor desenvolverá comportamentos que promovem a classe média. De maneira sutil, mas muito eficaz, ele acaba oportunizando os conteúdos contando com um repertório cultural, com um conhecimento prévio. Os alunos que não tiveram acesso ao conteúdo prévio necessário não serão capazes de abstrair o máximo de ensinamentos sobre o conteúdo em questão.

Adotando esse comportamento, ao invés de encurtar a distância causada pelo déficit de capital cultural entre os filhos dos trabalhadores da classe operária e da classe média, acaba-se acentuando ainda mais essa distância, e essa constatação é evidenciada pelo fracasso escolar. 


\section{A IDEOLOGIA, O PROFESSOR E A AUXILIAR: O QUE OS DADOS NOS REVELAM}

A escola, onde a pesquisa ocorreu, atendia a crianças da educação infantil ao Ensino Médio, nos turnos matutino e vespertino. Até abril de 2017, havia 652 alunos matriculados. Desse total, 145 crianças $(22,24 \%)$ pertenciam à educação infantil. A unidade educacional contava com um quadro de aproximadamente 100 funcionários, destes, 30 atuavam na Educação Infantil, sendo 16 professores, entre titulares de turma e especialistas (professores de educação física, de música e de inglês), quatro que pertenciam à equipe gestora - composta por uma coordenadora pedagógica e orientadora educacional, uma auxiliar de coordenação, uma assistente educacional e uma auxiliar educacional - todas do sexo feminino, também faziam parte do quadro 10 auxiliares de professoras. Além desses profissionais, a escola mantinha professores de atividades extracurriculares como ballet, futebol, judô, natação e capoeira, entretanto, esse grupo não integrou o rol de participantes da pesquisa.

Entre as auxiliares de professoras, cinco eram pedagogas recém-formadas, e cinco cursavam o ensino superior em Pedagogia. De acordo com os relatos que fomos anotando no decorrer da pesquisa, todas almejavam ocupar o cargo de professora titular de turma e se mostravam insatisfeitas com a posição que ocupavam. Diferentemente das auxiliares, as professoras não apresentavam interesse em ascender aos cargos de gestão. Todas que foram questionadas se posicionaram contrárias a tal ascensão, justificando satisfação pessoal com o trabalho desempenhado.

A insatisfação das auxiliares (grupo estigmatizado) pode ligar-se tanto aos salários recebidos, quanto às ações estigmatizadoras promovidas pelas professoras (grupo dos estabelecidos). Isso se evidenciou nos relatos registrados no decorrer da pesquisa, os quais, depois da análise, foram divididos em dois grupos: relatos que continham ações estigmatizadas ligadas à formação e à função.

As ações ligadas à formação foram aquelas em que estavam presentes na fala registrada das participantes, elementos que pareciam desconsiderá-las como parte do grupo de pro- 
fessoras/educadoras por estarem em formação ou por serem recém-formadas. Registro como o transcrito a seguir, foi muito comum no grupo das auxiliares.

Na Páscoa, a mãe do aluno "X" escreveu na agenda dele perguntando quem eram os professores que ficavam com seu filho, pois ela queria mandar um presentinho de Páscoa. A professora só colocou o nome dela e o dos demais professores especialistas, não colocou o meu. Quando eu perguntei porque ela não tinha colocado meu nome, ela me respondeu que a mãe tinha pedido o nome dos "professores”, e ela não sabia se a mãe queria que ela colocasse o meu nome também (AUXILIAR L. J.).

Nota-se pelo nosso registro que tanto para a auxiliar, quanto para a professora, havia uma clara divisão entre o ser professora e ser auxiliar, o que nos levou a inferir que, para a professora, tal pensamento poderia ligar-se à noção de pertencer a um grupo que se considerava superior ao das auxiliares, tanto por serem formadas há mais tempo, quanto por ocuparem um cargo considerado "superior". Já para a auxiliar, seu "lugar" era explicitamente considerado como menos importante em razão do próprio cargo ocupado.

Um exemplo de registro ligado à função e que também estava diretamente vinculado ao cuidado com as crianças pequenas pode ser encontrado no seguinte registro:

A professora não gosta de levar as crianças ao banheiro. Após ser questionada pela coordenadora, passou a levar os alunos ao banheiro, entretanto, se algum deles fizer cocô, ela deixa as crianças sozinhas no banheiro, e vem me chamar para limpar (AUXILIAR J. D.).

Muito comum encontrar entre as professoras que atuam na educação infantil e na população em geral o "menosprezo" pelo cuidado da criança, como se não fizesse parte das ações 
de caráter pedagógicas. A esse respeito Maria Malta Campos (1994) considera:

Voltadas para objetivos considerados como de caráter exclusivamente "pedagógico"”, as professoras - pois são quase todas - mulheres - gozam de prestígio, salário, condições de trabalho e progressão na carreira muito melhores [...] Este fato reflete-se na - percepção generalizada de que não são de sua responsabilidade tarefas identificadas com o trabalho "manual" ou doméstico, isto é, entendidas como próprias de funcionários de menor qualificação (CAMPOS, 1994, p. 33).

Tal fato esteve presente em boa parte dos relatos registrados o que, para nós, pareceu confirmar mais uma vez que, no local investigado, as professoras acreditavam que por terem formação em nível superior e muitas ainda em nível de pós-graduação, o desenvolvimento de trabalho de caráter mais manual não era adequado para elas. Décio Saes (2007) explicaria tal comportamento a partir da condição de classe. Para ele, sendo o professor pertencente à classe média, assume a ideologia dessa classe desqualificando todo e qualquer trabalho manual.

Já as auxiliares, que também parecem considerar o cuidado como trabalho de menor valor, desenvolvem-no por terem expectativas de ascensão profissional e, assim, cumprem com o que consideram como "obrigação", tendo em vista ficarem bem diante dos olhos de quem as pode estar avaliando.

\section{CONSIDERAÇÕES FINAIS}

Pensar a influência da ideologia no âmbito escolar é uma ação necessária para entendermos de que maneira ela opera e de que modo o profissional de educação serve à sociedade capitalista, realizando um trabalho de reprodução.

A escola, como aparelho ideológico de Estado, realiza durante a vida escolar do aluno a inculcação sobre a naturalidade das ações e da atual organização social, transferindo para esse aluno a total responsabilidade pelo seu sucesso ou 
fracasso no processo escolar, sem levar em consideração fatores econômicos e sociais.

Confirmou-se que, apesar dos diferentes discursos presentes na escola, prevalece a ideologia do professor (teórica e prática) em detrimento dos demais profissionais que coabitam o espaço escolar. É importante relembrar que a pesquisa fora desenvolvida em uma escola privada, localizada em bairro de São Paulo que atende à classe média alta, não sabemos se a investigação ocorresse em escolas públicas os resultados encontrados seriam os mesmos.

Com base na análise e reflexão dos registros realizados, foi possível afirmar que na relação estabelecida entre professoras e auxiliares na educação infantil, a estigmatização grupal, como fenômeno ideológico, é uma maneira de reproduzir a sociedade de classes dentro da escola. Os indivíduos, quando organizados em grupo visam manter a hegemonia desse grupo, e para isso, estigmatizam qualquer pessoa ou grupo considerado de menor importância ou de menor valor humano.

Os conflitos existentes na relação entre professoras e auxiliares estão enraizados nas questões ideológicas de classe. Apesar de haver um consenso entre os estudiosos e profissionais da área da educação que, tratando-se do atendimento à criança não pode haver distinção entre o cuidar e o educar, pois esses processos acontecem simultaneamente (CERISARA, 1999), a realidade escolar é composta por um quadro diferente, onde o trabalho pedagógico é desenvolvido pela professora e o trabalho manual pela auxiliar.

Perceber essa realidade é um passo importante para a quebra de paradigmas e uma reflexão sobre os caminhos da educação brasileira. É parte do trabalho do professor pensar e repensar sua prática, mas para isso, é preciso romper com o senso comum e pensar criticamente acerca do nosso papel na manutenção de nossa sociedade.

Faz-se necessário falar de ideologia de classes na escola justamente por fazer parte do cotidiano de todos os que frequentam o espaço escolar. Os indivíduos serão capazes de refletir a respeito de suas ações quando tiverem consciência da 
maneira como as noções ideológicas se manifestam na sociedade. Somente após a tomada de consciência, serão capazes de buscar uma sociedade mais justa e melhor para todos.

\section{REFERÊNCIAS}

CAMPOS, Maria Malta. Educar e Cuidar: questões sobre o perfil do profissional de Educação Infantil. In: BRASIL. Ministério da Educação e do Desporto. Secretaria de Educação Fundamental. Coordenação de Educação Infantil. Por uma política de formação do profissional de educação infantil. Brasília: MEC, p. 32-42, 1994.

ELIAS, Norbert; SCOTSON, John L. Os estabelecidos e os outsiders: sociologia das relações de poder a partir de uma pequena comunidade. Tradução de Vera Ribeiro. Rio de Janeiro: Jorge Zahar, 2000.

GOFFMAN, Erving. Estigma: notas sobre a manipulação da identidade deteriorada. Tradução de Márcia Bandeira de Mello Leite Nunes, 3. ed. Rio de Janeiro: Zahar Editores, 1980.

HARNECKER, Marta. Os conceitos elementares do materialismo histórico, 2. ed. São Paulo: Global, 1983.

LINHARES, L. L.; MESQUIDA, P.; SOUZA, L. L. Althusser: A escola como aparelho ideológico do estado. Congresso Nacional de Educação - EDUCERE, 7, 2007. Curitiba: Champagnat, 2007. Disponível em: <http://www. pucpr.br/eventos/educere/educere2007/anaisEvento/arquivos/CI-204-05. pdf $>$ Acesso em 17/04/2017.

PÉREZ GÓMEZ, A. I. As Funções Sociais da Escola: da reprodução à reconstrução crítica do conhecimento e da experiência. In: GIMENO SACRISTÁN, J.; PÉREZ GÓMEZ, A. I. Compreender e Transformar o Ensino, 4. ed. Porto Alegre: ArtMed, 1998.

SAES, Décio. Classe média e escola capitalista. Crítica Marxista. Cemarx, IFCH, UNICAMP, $\mathrm{n}^{\circ} .21,2005$.

SAES, Décio. A ideologia docente em 'A Reprodução', de Pierre Bourdieu e Jean-Claude Passeron. Educação Linguagem, v. 10, p. 106-126, 2007.

\section{SOBRE AS AUTORAS}

\section{Jéssica Tavares Luz}

Tem graduação em Administração de Empresas pela Universidade Metodista de São Paulo, Professora Auxiliar de uma escola privada no município de São Paulo e graduanda em Pedagogia também pela Universidade Metodista de São Paulo (UMESP).

E-mail: jessica.luz02@gmail.com 


\section{Cassia Domiciano}

Doutora em educação pela Universidade de Campinas (UNICAMP). Professora auxiliar do Programa de Pós-Graduação em Educação da Universidade Metodista de São Paulo (UMESP). Desenvolve pesquisas na área de política, gestão e financiamento da educação, com ênfase na Educação Infantil.

E-mail: cassia.domiciano@metodista.br 